\title{
THE VOLATILES OF COCOA BY GC/MS ANALYSIS AND SENSORY EVALUATION WITH SPECIAL EMPHASIS ON THE EFFECT OF FERMENTATION TIME AND MATURATION
}

\author{
D. D. ABEYGUNASEKERA, A. M. MUBARAK AND E. R. JANSZ \\ Ceylon Institute of Scientific and Industrial Researcb, P.O. Box 787, 363, Bauddbaloka \\ Mawatha, Colombo 7.
}

(Date of reccipt : 17 January 1989)

(Date of acceptance : 23 August 1989)

\begin{abstract}
The effect of fermentation time and the maturation process on the volatiles of cocas (Theobroma cacao L) grown in Sri Lanka is reported. Appruximately 35$75 \%$ of the volatiles (depending on sample) have been identified by GC/MS. Both fermentation time and the maturation process increase the level of volatiles of 4 day fermented cocoa but the resulting flavour profile is different. Sensory analysis showed that flavour score had a linear response to fermentation time and flavour improved significantly with time. The sensory evaluation panel also found that maturation improves flavour and that chocolate from Grade 111 beans had a better flavour than that from Grade I beans.
\end{abstract}

\section{Introduction}

In the early 1960's only a few of roasted cocoa's volatiles had been identified, but by 1972 over 300 volatiles has been identified. ${ }^{7}$ Among the significant studies were that of Marion et al. ${ }^{7}$ who by gas chromatographic separation and mass spectrometric and ir spectroscopic identification described 91 components including 35 of them for the first time among them being 6 pyrazines, ${ }^{10}$ Later studies by $\mathrm{GC} / \mathrm{MS}^{5,9}$ resulted in the identification of 13 further compounds and showed that the most abundant group of volatiles from fermented beans were alcohols and esters while that from roasted beans were pyrazines and aldehydes. However, the effect of fermentation time on specific components of unroasted and roasted cocoa except in a few instances, had not been reported. Barel et al. ${ }^{4}$ showed that the production of pyrazines by roasting was related to fermentation time and that $2,3,5,6$ - tetramethyl-pyrazine reached a maximum after seven days fermentation.

The effect of the maturation process 8.14 on individual chemical components of cocoa has been even less documented, where apart from studies of the authors group ${ }^{1,2,3,13}$ no detailed reports have been found in the literature. The effect of fermentation time and the maturation process on the volatiles has been studied by gas chromatography - Mass spectrometric (GC/MS) analysis. Sensory evaluation of chocolate made on a laboratory scale from cocoa beans subjected to various fermentation times and a 48 hour maturation process followed by roasting is also reported. 


\section{Experimental}

\subsection{Plant Material}

Theobroma cacao pods were obtained from Wariyapola Estate, Matale, Sri Lanka in the major season (September to December) of 1987.

\section{2,2 Fermentation}

The basket method was employed to ferment cocoa beans. ${ }^{12}$ Each basket contained 12-17 kg beans and pulp and fermentation lasted upto 6 days. Samples (one basket each) were drawn on the 2 nd, 4 th and 6 th days respectively for experimental purposes.

\subsection{Maturation}

Cocoa beans $(10-15 \mathrm{~kg}$ ) were subjected to the maturation process after the 4 th day of fermentation, by holding the beans (spread on coir matting, in a layer of $5 \mathrm{~cm}$ ) at an ambient temperature $\left(28^{\circ}-29^{\circ} \mathrm{C}\right)$ with little drying in the shade. The period of maturation was 48 hours. Turning of the beans were carried out after $24 \mathrm{~h}$ to ensure proper aeration.

\subsection{Drying and Roasting}

Cocoa beans, control (unfermented) and treated were sun dried by spreading on coir matting ( $3-4$ days). The dried beans were spread on a tray and roasted at $140^{\circ} \mathrm{C}$ for $30 \mathrm{~min}$ in a Memmert UL 50 oven.

\subsection{Extraction and Trapping of Volatiles}

Cocoa powder (100 g) obtained by grinding roasted and deshelled cocoa beans were placed in a round bottomed flask $(500 \mathrm{ml})$ with distilled water $(275 \mathrm{ml})$. Extraction and trapping of the volatiles were carried out using a modified Likens and Nickerson apparatus, with isopentane : diethyl ether $(1: 1)(25 \mathrm{ml})$ as the trapping solvent. The extract was evaporated in a concentration tube using a water bath $\left(30^{\circ} \mathrm{C}\right.$ ) to a volume of $1 \mathrm{ml}$ (approximately $20--30 \mathrm{~min}$ ).

\subsection{Identification of Volatiles by GC/MS}

Analysis of the cocoa volatiles $(1: 0 \mu 1)$ was carried out using a Shimadzu Gas Chromatograph-Mass Spectrometer (GC/MS-QP 1000A) linked on line to a CRT (Cathode Ray Tube) display equipped with a printer-plotter.

\section{GC/MS Operating Parameters}

Column

: $\quad \mathrm{SPB}-1$ (SE 30) fused silica capillary column $(0.25 \mu \mathrm{m}$ film), $30 \mathrm{mx}$ $0.32 \mathrm{~mm}$ ID 
Temperature Programme

Injection temperature

Column head pressure

Make up gas

Injection

Interface

Ionisation source

Resolution

Mass range
: 1 min at $35^{\circ} \mathrm{C}$ then to $230^{\circ} \mathrm{C}$ at $8^{\circ} \mathrm{C} / \mathrm{min}$ and hold $15 \mathrm{~min}$

: $\quad 280^{\circ} \mathrm{C}$

: Helium, $0.8 \mathrm{~kg} / \mathrm{cm}^{2}$

: Helium, $20 \mathrm{ml} / \mathrm{min}$

: Splitless injection with 0.5 min wait time

: Glass jet separator, $250^{\circ} \mathrm{C}$

: $\quad \mathrm{EI}, 70 \mathrm{eV}, 60 \mu \mathrm{A}$ at $250^{\circ} \mathrm{C}$

$: \sim 2000$

: $\quad 10 \sim 1000$

Identification of volatile components were carried out with the aid of mass spectral data in the computor data bank and the eight peak index of mass spectra. ${ }^{16}$ In addition, most of the alcohols, aldehydes and pyrazines were identified using authentic standards.

\subsection{Quantification of Volatile Flavour Constituents}

Quantification of volatile flavour constituents was carried out by GC/FID using the same parameters given in Section 2.6 using the Shimadzu Gas Chromatograph GC-9A linked to a Shimadzu C-3RA Chromatopak data processor. Nonanoic acid was used as the internal standard.

\subsection{Sensory Analysis}

Chocolate samples were prepared on a laboratory scale ${ }^{11}$ using cocoa beans that had been subjected to fermentation, maturation and roasting.

These samples were evaluated by a trained taste panel of the Ceylon Institute of Scientific and Industrial Research (CISIR) using standard techniques. ${ }^{6}$ The samples were marked for flavour with a scoring system out of a total of 50 .

\section{Results}

\subsection{Volatiles by GC/MS Analysis}

Results of studies on chemical components of cocoa are shown in Table 1, where fermentation time was 0 (control), 2,4 and 6 days. In addition a 4 day fermented sample was subjected to the maturation process. 
Table 1. Volatile constituents of cocoa with fermentation and maturation

\begin{tabular}{|c|c|c|c|c|c|}
\hline Compound & $\mu \mathrm{g} / \mathrm{g}$ & $\mu \mathrm{g} / \mathrm{g}$ & $\begin{array}{l}4 \mathrm{FR} \\
\mu \mathrm{g} / \mathrm{g}\end{array}$ & $\begin{array}{l}4 \mathrm{~F} \\
2 \mathrm{MR} \\
\mu \mathrm{g} / \mathrm{g}\end{array}$ & $\mu \mathrm{g} / \mathrm{g}$ \\
\hline Methylcyclohexane & 0.49 & 0.67 & 2.10 & 3.50 & 2.70 \\
\hline 3-Methylbutan-1-ol & 0.07 & 0.54 & 4.54 & 3.04 & 4.77 \\
\hline Toluene & - & - & 1.96 & 2.96 & 2.11 \\
\hline $\mathrm{n}$-hexanal & - & - & 2.53 & 2.38 & 3.50 \\
\hline 3-methylbutyl acetate & 0.09 & 0.24 & 3.46 & 4.56 & 6.54 \\
\hline Heptan-2-ol & - & - & 1.66 & 1.07 & 2.87 \\
\hline 2,5 dimethylpyrazine & - & - & 1.22 & 1.86 & 2.34 \\
\hline Benzaldehyde & $\cdot-$ & 0.07 & 3.52 & 4.97 & 4.39 \\
\hline 5 -methyl-2-furfural & - & 0.07 & 1.67 & 2.46 & 4.40 \\
\hline 2,3,5-trimethylpyrazine & - & - & 1.68 & 1.84 & 2.10 \\
\hline 2-ethyl-3-methylpyrazine & - & - & 1.28 & 3.07 & 1.58 \\
\hline Phenylacetaldehyde & - & 2.04 & 4.77 & 4.32 & 4.82 \\
\hline Acetophenone & - & 0.21 & 0.36 & 0.39 & 1.17 \\
\hline 3-ethyl-2,5-dimethylpyrazine & - & 0.10 & 0.17 & 0.18 & 0.25 \\
\hline $2,3,5,6$-tetramethylpyrazine & - & 0.34 & 0.61 & 0.92 & 1.08 \\
\hline 2 -phenylethan-1-ol & - & - & 0.33 & 0.10 & 0.08 \\
\hline Ethyl phenylacetate & 0.04 & 0.84 & 2.85 & 5.72 & 3.62 \\
\hline 2-Phenylethyl acetate & 0.09 & 0.43 & 0.48 & 1.56 & 0.84 \\
\hline Indole & - & - & 0.24 & 0.44 & 0.52 \\
\hline Eugenol & 0.02 & 0.19 & 0.25 & 1.15 & 0.46 \\
\hline 2-Butyl-3,5-dimethylpyrazine & - & - & 0.71 & 1.38 & 1.29 \\
\hline Ethyl decanoate & 1.41 & 2.43 & 3.59 & 3.52 & 3.91 \\
\hline Ethyl dodecanoate & 0.04 & 0.89 & 1.40 & 2.22 & 4.47 \\
\hline Ethyl tetradecanoate & 0.47 & 0.72 & 1.15 & 1.10 & 1.90 \\
\hline Heptandecan-2-one & 0.14 & 0.64 & 1.06 & 1.96 & 1.25 \\
\hline Ethyl hexadecanoate & 0.29 & 0.89 & 2.15 & 2.33 & 2.51 \\
\hline Ethyl octadecanoate & 0.34 & 0.90 & 1.34 & 3.45 & 1.58 \\
\hline Total identified $(\mu \mathrm{g})$ & 3.4 & 12.2 & 47.0 & 62.4 & 67.0 \\
\hline $\begin{array}{l}\text { Total volatiles } \\
\text { (identified + unidentified) } \\
(\mu \mathrm{g})\end{array}$ & 9.5 & 28.9 & 60.6 & 84.9 & 87.3 \\
\hline$\%$ Identified & 35.7 & 42.2 & 77.5 & 73.4 & 76.7 \\
\hline NFR - Non fermented roasted & $\operatorname{coc} a d$ & & $4 \mathrm{~F} 2 \mathrm{M}$ & $\begin{array}{r}-4 \text { day } \\
2 \text { day } \\
\text { and roa }\end{array}$ & $\begin{array}{l}\text { mented } \\
\text { natured } \\
d \text { cocoa }\end{array}$ \\
\hline
\end{tabular}

2FR -2 day fermented and roasted cocoa

$4 \mathrm{FR}-4$ day fermented and roasted cocoa

$6 \mathrm{FR}-6$ day fermented and
roasted cocoa

The sequence of volatiles are arranged in order of appearance in the gas chromatographic separation. 
Results show that total volatiles increase markedly with fermentation time. The general increase is reflected among all the flavour constituents identified. Although the maturation process increases volatiles in a 4 day fermented sample almost to the level of a 6 day fermented sample the resulting flavour profile differs. However, no consistent trend is discernable among the groups of compounds to conclude that any one group is preferentially formed or lost during maturation. For example, some pyrazines are higher in the matured sample while others are higher in the 6-day fermented nonmatured sample.

\subsection{Sensory Evaluation}

The relationship between days of fermentation and flavour score (of chocolates) was found to be linear. The coefficient of variation was $27 \%$ and the response equation can be given as $\mathrm{y}=10.5+3.8 \mathrm{x}$ (Figure 1 ) with a correlation coefficient of 0.996 .

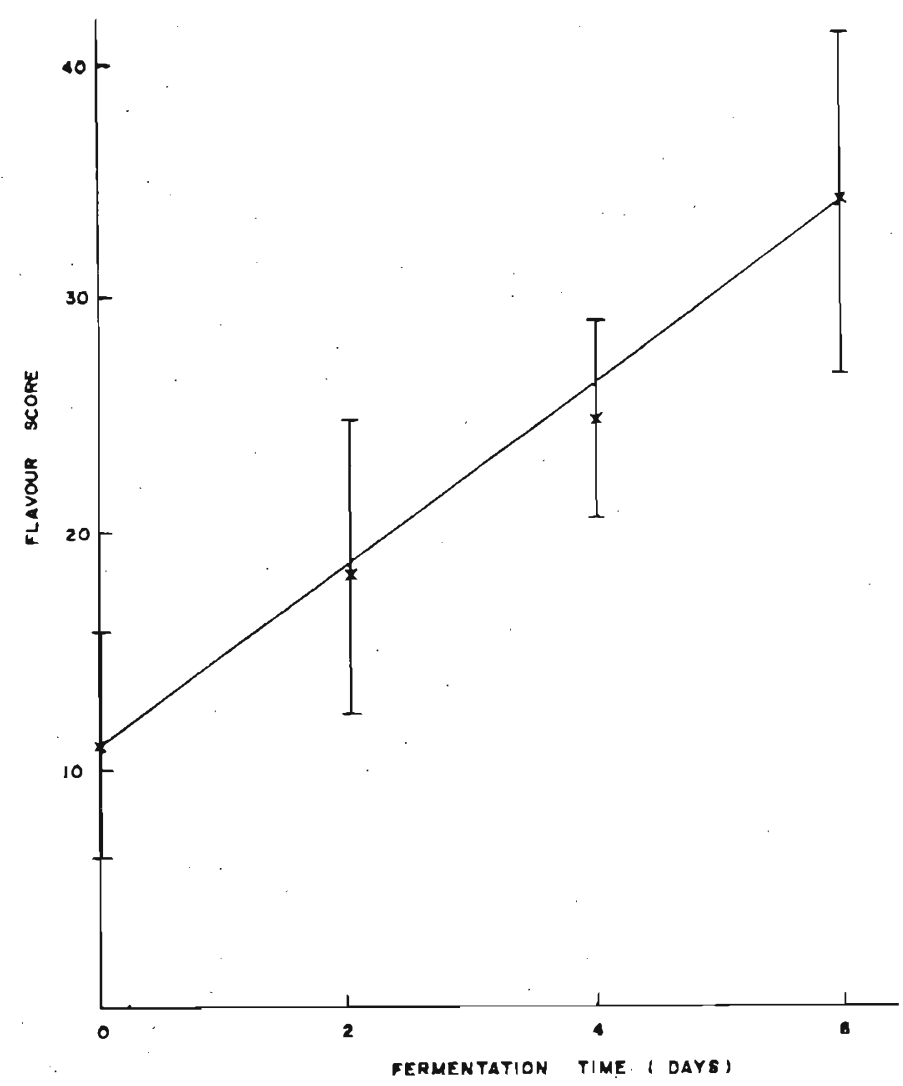

Figure 1. Effect of fermentation time on flavour score The vertical bars represent standard deviations 
The mean flavour score for cocoa that was matured was 31.6 and nonmatured was 23.9. The paired t test of the above 4 day fermented, matured and non-matured samples gave a result of 2.89 and is significant at the $2 \%$ level showing that there is a difference between the two types - the matured sample scoring significantly higher. However, on comparing the 4 day fermented, matured sample with a 6 day non-matured sample, no significant difference in scores were obtained.

A simultaneous set of experiments using Grade I and Grade III beans obtained from the cocoa trade gave the following results. The mean flavour score for Grade I beans was $14.7 \pm 4.2$ and Grade III beans, $23.6 \pm 2.0$.

\section{Discussion}

Both GC/MS analysis and sensory evaluation indicate that increasing fermentation time even up to 6 days improves flavour content. This is not surprising as Sri Lankan cocoa is mainly the forestero variety. ${ }^{12}$

GC/MS analysis shows that the flavour profile for a 4 day fermented cocoa bean differs on 2 days maturation when compared to 2 extra days fermentation. This is also not surprising as the conditions for maturation differ from that of fermentation (both the degree of aerobicity and temperature are different and would influence biochemical reactions). However, the results are too complex and as such it is difficult to draw any further conclusions.

Sensory analysis shows that maturation of 4 day fermented cocoa can result in an improvement in flavour. Using the most pessimistic interpretation it could be stated that holding 4 day fermented beans under ambient conditions appears not to harm cocoa flavour.

In sensory analysis the Grade III beans gave a significantly higher flavour score than Grade I beans. Once again this is not surprising as grading of cocoa in Sri Lanka is purely by visual characteristics ${ }^{15}$ and generally Grade I cocoa is underfermented. However, these results are subject to the limitations of other subjective evaluations of flavour.

\section{Acknowledgement}

The authors thank the Superintendent, Wariyapola Estate, Matale, for his cooperation during the sampling of cocoa. Mr. Valentine Abeywardene for statistical analysis, Mr. D. J. Abeyaratne for assistance in GC/MS analysis, Mrs. D. S. T. Warnasuriya for assisting in the collection of literature and Mrs. I. Bandara for secretarial assistance. This paper forms part of the M. Phil thesis of one of the authors (D. D. Abeygunasekera). 


\section{References}

1. ABEYGUNASEKERA, D.D. (1990) Some chemical studies on the processing of cocoa with special emphasis on flavour components. M. Phil thesis University of Colombo, Sri Lanka.

2. ABEYGUNASEKERA, D.D., JANSZ, E.R. (1989) J. Natn. Sci. Coun. Sri Lanka 17(1) In Press.

3. ABEYGUNASEKERA, D.D., JANSZ, E.R. (1989) J. Natn. Sci. Coun. Sri Lanka 17(1) In Press.

4. BAREL, M., LEON, D. VINCENT, J.C. (1985) Cafe, Cacao. $29: 277$,

5. Gill, M., MACLEOD, A.J., MOREAU, M.C. (1985) Dev. Food Sci $10: 261$.

6. INDIAN STANDARDS INSTITUTION (1971) Guide for sensory evaluation of food Part 2. Methods and evaluation cards, IS 6273:1971.

7. KEENEY, D.G. (1972) Various interactions in chocolate flavour J. Amer. Oil Chemists Society, $49: 567$.

8. LIAU, H.T.L. (1976) Tecbnical Bulletin No. 2. Department of Agriculture, Sabah, Malaysia.

9. MACLEOD, A.J., GILL, M.S., MOREAU, M. (1984) Pbytochemistry, 23 : 1937.

10. MARION, J.P., MUGGLER-CHAVAN, F., VIANI, R., BRICOUT, J. REYMOND, D. EGLI, R.H. (1967) Helv. Chim. Acta, $50: 1509$.

11. MINIFE, B.W. (1982) In : Chocolate, cocoa and confectionary Science and Technology, Second edition, AVI Publishing Company Westport Connecticut, p. 134.

12. OGUTUGA, D.B.A. (1976) In : Cocoa processing in Sri Lanka UNDP/FAO project of Research and Experimentation on minor export crops Sri Lanka.

13. PACKIYASOTHY, E.V. (1982) Studies on curing of cocoa and cocoa waste. M.Sc. Thesis, University of Sri Jayawardenepura, Sri Lanka.

14. SCHWARTZ, P.B., WONG, D.Y.C., BRIDGER, R. (1981) Planter, Kuala Lumpur, 57 : 584,

15. BUREAU OF CEYLON STANDARDS (1977) The Standard Specifications of Cocoa beans, Bureau of Ceylon Standards, First Revision SLS : 106 (1977).

16. Eight peak index of mass spectra (1983) 3rd. ed. Volume 2 Parts I and II. Published by the mass spectrometry data centre. The Royal Society of Chemistry, Nottingham, U.K. 